Motrivivência Ano XXIII, No 36, P. 291-305 Jun./2011

doi: 10.5007/2175-8042.2011v23n36p291

\title{
TRABALHO E LAZER NA INFÂNCIA E ADOLESCÊNCIA NO SÉCULO XXI: DIREITO SOCIAL OU INCLUSÃO EXCLUDENTE?
}

\author{
Graziany Penna Dias' \\ Marcelo Silva dos Santos²
}

\section{RESUMO}

O presente artigo tem por intenção discutir as relações entre trabalho, lazer, infância e adolescência, hodiernamente, com base nas mudanças por que vem passando os países do capitalismo periférico na América Latina. Trabalho e lazer são esferas centrais e indissociáveis para o ser humano e as quais ele não pode prescindir para existir. O que se vem constatando é que essas vêm passando por um processo de inclusão excludente. Faz-se necessário resgatar a partir da infância e da adolescência a visão do ser humano, enquanto sujeito coletivo e histórico capaz de produzir e transformar a realidade que o cerca.

Palavras-chave: Trabalho, Lazer, Inclusão/Excludente.

\section{Introdução}

O presente artigo tem por intenção discutir as relações entre trabaIho, lazer, infância e adolescência, na atualidade, com base nas mudanças por que vem passando os países do capitalismo periférico na América Latina. Nosso objetivo é contribuir com o debate que se tem travado

1 Professora de Educação Física, Mestre em Educação e membro/pesquisador do Grupo de Estudo Trabalho, Educação e Materialismo Histórico (GETEMHI) e do Coletivo de Estudos de Política Educacional - Fundação Oswaldo Cruz - FIOCRUZ/RJ (Núcleo Juiz de Fora/MG). Contato: graziany.dias@ifsudestemg.edu.br

2 Professor da Faculdade Sudamérica no curso de Licenciatura em Educação Física na cidade de Cataguases/MG e da Rede Municipal de Juiz de Fora/MG. Contato: marceloss2003@ig.com.br 
no campo do trabalho e do lazer em face da reestruturação produtiva que vem acontecendo no mundo e vem trazendo impactos profundos nestas duas esferas.

Trabalho e lazer são, reconhecidamente por diversos autores dessas áreas, duas esferas centrais indissociáveis para o ser humano e delas este não pode prescindir para existir. $\mathrm{O}$ que se vem constatando é que estas vêm passando por um processo de inclusão excludente.

Assim, iniciaremos por compreender essas duas esferas e suas mudanças ao longo dos tempos.

\section{Um diálogo com trabalho e lazer}

Trabalho e lazer são esferas que possuem suas especificidades, mas que devem ser tratadas de forma inter-relacionada. Na literatura é muito comum encontramos estudos que tratam de suas especificidades, de forma conjunta. É, nesse sentido, que buscaremos apontar as relações históricas e contemporâneas referentes a constituição desses fenômenos. Para isto nos valeremos principalmente dos estudos de Melo et al. (2003), Werneck (2000).

Na modernidade, um momento que é bem considerado nas análises sobre o trabalho e lazer é o último quartel do século XVIII, na qual a organização do trabalho foi, vertiginosamente, transferida para as fábricas o que implicou na chamada artificialização dos tempos de trabalho e não-trabalho.

Em outras palavras, o tempo diário da vida passou a ser demarcado pela jornada de trabalho, que, aliás, foi absurdamente, excessiva nos momentos iniciais do capitalismo (cerca de 12 a 16 horas de trabalho).

Foi/é um momento da história da humanidade que o homem teve/tem de se submeter à máquina. Inclusive, um filme clássico que retrata bem esta situação, fazendo uma crítica contundente é "Tempos Modernos", de Charles Chaplin na qual o homem passa a ser assimilado pelo processo produtivo em que, praticamente, torna-se um apêndice da máquina na qual tem de submeter.

3 Para efeitos deste texto não adentraremos com muita profundidade na questão do tempo observado sob o viés econômico. Apenas iremos demarcar com base nos estudos de Marx em um de seus textos "Salário, Preço e Lucro" de que o valor de uma mercadoria (que no mercado vai ser monetarizado na forma de preço) tem relação com o tempo socialmente necessário para produzir uma determinada mercadoria. E nesta lógica quanto menos tempo de produção, menor o valor de cada mercadoria produzida, e, por sua vez, menor o preço. Isto possibilita vender produtos mais baratos e abocanhar maiores fatias do mercado, o que, sem o qual, não é possível sobreviver à concorrência intercapitalista (MARX, 2004). 
O tempo ${ }^{3}$, assim, passa a ser a medida primordial para a classe capitalista auferir seus lucros. Não obstante, a expressão "tempo é dinheiro" passa a ser uma máxima até os dias de hoje. $E$, nessa lógica, os tempos passaram a ser artificializados, como já anotamos anteriormente, sendo a partir desse processo, que podemos dizer que o lazer "aparece" ${ }^{4}$ tal como nós o conhecemos hoje. Ou seja, diferentemente, dos momentos históricos precedentes, a humanidade passa a ter os tempos de trabalho e não-trabalho definidos e inclusive regidos por lei, principalmente ao final do século XIX e começo do XX.

Nesse período, o mundo passou por crises dos modelos econômicos e políticos da época (especialmente com a Primeira Guerra Mundial). Segundo Chemin (2003), a criação dos direitos sociais em esferas como o trabalho e lazer vão se dar neste contexto turbulento do mundo capitalista que temendo a disseminação das ideias socialistas começa a promover garantias mínimas de sobrevivência para a massa de cidadãos/trabalhadores. É importante frisar que isso foi feito com o intuito de manutenção do modo de produção capitalista.

De qualquer modo para a classe trabalhadora o tempo de trabalho, seja nos séculos passados como atualmente, é um tempo penoso, aviltante das condições humanas e em nada se assemelha com a perspectiva ontológica, work (ANTUNES, 2004), na visão de pensadores como Marx, que concebiam o trabalho ${ }^{5}$ como autofundador $^{6}$ do ser humano. Mas se aproxima da visão que Marx havia atribuíra ao trabalho na sua forma histórica, labor (ANTUNES, 2004), ou seja, dotado de um conteúdo negativo. Representa o trabalho alienado, explorado. O trabalhador não se reconhece na produção, não tem acesso ao produto de sua produção, não se reconhece enquanto fazendo parte do gênero humano (ibid.).

4 Optamos por colocar em aspas esta palavra com o intuito de chamar atenção de que o lazer não surge por acaso, mas que foi/é construído, historicamente, pelos homens.

5 Marx e Engels conferiam ao trabalho um conteúdo positivo, pois na sua origem o trabalho seria da necessidade e vontade humanas, revelando a capacidade criadora do homem, na qual o desejo se projetaria no futuro (teleológico) e sua realização se daria a partir de um conjunto de ações para a consecução de seu objeto. Para saber mais ver Marx (1999; 1985) e Antunes (1999; 2004).

6 Por meio do processo de trabalho temos uma dupla transformação. Por um lado o próprio ser humano que trabalha é transformado pelo seu trabalho, pois ele atua na natureza, desenvolve as potências nela adormecidas ou ocultas e subordina as forças da natureza ao seu poder; por outro lado as forças da natureza são transformadas em meios, em objetos de trabalho, em matériasprimas, entre outros (ANTUNES, 2004, p. 227). 
$E$, na vigência dessas condições, o trabalho passa a ser, amplamente, valorizado na sociedade lazer passou a ser encarado pelos trabalhadores como um momento de compensação das frustrações geradas no seio dos processos produtivos. Somado a isto, as condições de trabalho que eram as mais inóspitas possíveis. Segundo Victor e Edmundo (2003) sobre as condições daquela época (séc. XVIII/XIX).

De fato, era uma compreensão da classe dominante manter a pobreza dos trabalhadores, criando uma necessidade constante de trabalho e mantendo o exército de mão-de-obra disponível. Observamos que um excedente de mão-de-obra disponível fora gerado com a própria criação e adoção das máquinas a vapor ${ }^{7}$, pois estas substituíram muitos trabalhadores (p. 08).

Tais fatos promoveram insatisfações que culminaram com lutas organizadas dos trabalhadores que iniciaram reivindicações por melhores condições de vida bem como o aumento do tempo "livre".

De acordo com Werneck (2003a), nas primeiras décadas do séc. XX foram acirradas as disputas entre capital e trabalho nos diversos países industrializados, ou em vias de industrialização, no que tange a regulamentação e redução da jornada de trabalho, o que implicou no aumento do "tempo livre".

E isto trouxe ações da classe dominante no tocante a ter uma maior preocupação com o tempo de não-trabalho, pois este poderia atrapalhar o período de trabalho, pelos seguintes motivos: primeiro que as diversões eram tidas como perigosas e perniciosas já que, para além de manter os antigos estilos de vida (como festas, noitadas) o que poderia deteriorar as forças físicas dos trabalhadores; segundo que era um momento em que os trabalhadores se reuniam e poderiam tomar consciência de sua situação promovendo uma intensificação das lutas e resistências. Talvez esse segundo motivo fosse o mais preocupante do que o primeiro. Nas palavras de Werneck.

Na Europa do século XIX, o encontro dos operários em alguns

7 Aqui gostaríamos de acrescentar que embora as máquinas a vapor tenham possibilitado a transferência da força muscular humana para a máquina isto, por si só, não implicou na diminuição dos postos de trabalho da época. De acordo com Fiod, apoiada em Marx: "Os processos produtivos não tem o poder de desqualificar, alienar e de explorar produtivamente os indivíduos. As relações entre os homens que deles se apoderam é que determinam o que eles serão nesta forma de sociedade: eis seu caráter social" (1999, p. 100). 
locais ao final do expediente, tais com pubs e cafés, alcançaram proporções muito perigosas aos olhos da burguesia, que ultrapassavam a dimensão do lazer enquanto busca de prazer e realização. Essa preocupação voltava-se não para o perigo do lazer possibilitar a ocorrência do vício, mas para a sua utilização como pretexto para reunir os operários interessados em promover a mobilização política e o questionamento das suas reais condições de vida (2000, grifo da autora, p. 50).

Assim, as diversões passaram por um destacado controle por parte das classes dominantes por meio da articulação entre o poder judiciário, força policial e Igreja. Podemos constatar, novamente, a lógica do licere, porém não mais pela perspectiva religiosa, mas econômica, ou seja, só seria permitido o que não fosse atrapalhar os processos de produção (VICTOR e EDMUNDO, 2003).

Uma iniciativa das classes dominantes foi reorientar as práticas populares de diversão dos trabalhadores, oferecendo (ou impondo) uma possibilidade controlada de divertimento. Nesta linha, muitas manifestações da cultura foram sendo perseguidas, como as touradas, brigas de galo, entre outras formas de diversão consideradas bárbaras e atrasadas.

Em substituição as ditas barbaridades, as classes dominantes ofereciam o esporte moderno (ASSIS, 2001; BRACHT, 2005) com todos os seus códigos, normas e sentidos que pudessem inscrever a população nos quadros modernos do capitalismo.

Somado ao processo de controle, que viemos destacando até então, abriu-se as também as portas para a mercadorização do lazer que ao longo do séc. XX, e com grande força a partir de 1970, o lazer passa a ser um dos grandes filões a serem explorados pela grande indústria do entretenimento.

E sua perspectiva avança para formas mais tangíveis de práticas de lazer. Os avanços tecnológicos têm transferido as relações humanas para o isolamento na multidão. As relações têm sido mediadas pelos equipamentos disponíveis que impõem uma diminuição do contato entre as pessoas e com a natureza.

Se por um lado as tecnologias, como a internet, impõem contatos nunca considerados possíveis entre as pessoas separadas geograficamente (BRUHNS, 2001). Por outro tem trazido novas sociabilidades que deslocam o contato humano para o contato estabelecido pela tela. Desloca-se para a máquina a convivência. Desloca-se o real para a imagem.

No tocante as relações humanas, estas passam a transitar, 
juntamente, como as mercadorias, para a "sociedade do descarte". Descarte de bens produzidos. Descarte dos valores, estilos de vida, relacionamentos estáveis, enfim a busca das formas mais imediatas e tangíveis de relação humana.

$\mathrm{Na}$ esfera do lazer isto tem remetido a novas formas de diversão com visto nas lan-houses. Na lógica da sociedade de consumo o lazer tem sido posto como a promessa da grande indústria cultural na qual sua mercadorização tem afastado o lazer como um direito social. O lazer passa a ser concebido, portanto, como um mero entretenimento, promovendo a distração alienante para escapar do tédio e matar o tempo (WERNECK, 2000).

Baseado nas considerações feitas anteriormente, passaremos para a discussão do trabalho e lazer na infância e na adolescência buscando compreender se esses primeiros têm se configurado enquanto direitos sociais ou mercadoria.

\section{Trabalho e lazer na infância e adolescência no século XXI: direito social ou inclusão ex- cludente?}

Como vimos, no século passado o Trabalho e o Lazer passaram por significativas mudanças no mundo capitalista. E, claro, isto trouxe profundos impactos para a infância e a adolescência, fato este que trataremos a seguir.

Entendemos que faz importante, antes, resgatarmos em caráter mais explicativo, como era visto o trabalho na infância e na adolescência o que nos dará maior fôlego nas discussões seguintes.

De acordo com Silva (2003) o trabalho na infância já existia muito tempo antes do trabalho fabril (séc. XVIII). Nas sociedades primitivas o trabalho já fazia parte da vida da criança e do adolescente, porém ele cumpria um significado bem diferente dos tempos modernos.

O trabalho era dotado de valor útil e sua perspectiva era pautada em dois parâmetros: formação e sociabilidade. A economia, na idade média, por exemplo, estava assentada na agricultura pastoril, na qual a criança e o adolescente eram aliados à lida da terra, participando do processo de integração do trabalho como valor útil de manutenção da existência humana, sem muita exploração e sem que isso fosse danoso e prejudicial ao seu desenvolvimento (SILVA, 2003). As atividades afins ao trabalho procuravam acompanhar o ritmo biológico e cultural das crianças e dos adolescentes da época.

Porém, com a revolução industrial e o advento da maquinaria, 
processo descrito por Marx (1985), uma nova configuração e sentido do trabalho passa a entrar em cena, pois o desenvolvimento técnico da fábrica possibilitou o ingresso de um enorme contingente de crianças e adolescentes para o seu interior com jornadas extenuantes de trabaIho que podiam variar entre 14/16 horas diárias.

Os ritmos e processos de trabalho impostos excediam em muito as capacidades físicas das crianças e adolescentes, pondo em descompasso o seu ritmo biológico e reduzindo a sua vivência cultural da infância, já que o tempo de não trabalho era bastante reduzido.

Não obstante, isto trouxe diversos problemas à Inglaterra e outras nações (séc. XVIII/XIX), palco da ascensão capitalista industrial. De um lado isto foi gerando uma insatisfação generalizada à classe trabalhadora da época, pois além de ter de se confortar com o trabalho penoso, ele teve de assistir suas crianças e adolescentes se baterem também com aquela lógica destrutiva, que gerava, inclusive, muitos óbitos.

De outro lado o próprio Estado inglês se via com problemas graves produzidos pela exploração do trabalho infantil. Segundo Soares (2004), a degradação do trabalho em relação ao púbico infantil era tamanha que a população oriunda deste processo começou a ter um decréscimo na sua estatura média, que era uma referência na época para se ingressar nas forças militares.

A debilidade física era tal que os homens não mais atingiam a altura mínima exigida para o ingresso na tropa, problema que obrigou o exército francês e o alemão, ao longo século XIX, a diminuir paulatinamente a altura mínima exigida, pois, caso essa medida não fosse tomada, não haveria homens disponíveis para o serviço militar (SOARES, 2004, p. 24).

Dessa forma, ocorreu a intervenção do próprio Estado capitalista da época. De acordo com Nogueira,

Tratava-se, assim, de restringir os poderes ilimitados do capitalista sobre as condições de utilização da força de trabalho, com a finalidade de preservá-la. [...] Se a classe dirigente - ou uma fração dessa classe - se viu forçada a forjar os próprios instrumentos de seu autocontrole, é que uma necessidade histórica se impôs e que os objetivos de longo prazo superaram a exigência imediata de lucro (1990, p. 54).

Assim, tem-se o início a determinação de leis, regras que possam permitir a regulação capitalista em sua exploração desenfreada. Aliás, segundo Nogueira (1990) as crianças foram o primeiro 
público, na história da humanidade, que começou a ter regulamentada a sua jornada de trabalho e que mais tarde se estendeu a toda classe trabalhadora.

No Brasil, isto começou a se figurar na virada do século XIX/ XX. O país começou a legislar sobre algum direito social para crianças e adolescentes com o intuito de promover a estabilidade social que permitisse o capitalismo avançar. Como exemplo disto podemos citar o Decreto de 1.313/1891 que regulamentava o trabalho dos menores nas fábricas da capital federal.

Segundo o Decreto 1313/1891 ficava proibido o trabaIho noturno aos menores de 15 anos e qualquer forma de trabalho antes 12 anos. Definia ainda que:

- os menores do sexo feminino 12-15 anos teriam jornada máxima de 7 horas por dia.

- os menores de sexo masculino entre 12-14 teriam jornada máxima de 9 horas por dia.

O Decreto 17.934-A, de 12/10/1927, tratava do trabalho dos menores, na qual definia a idade mínima de 12 anos, mantida no Código de Menores, e proibia o trabalho noturno de menores de 18 anos de idade.

No governo de Getúlio Vargas, várias medidas em "benefício" dos trabalhadores, sejam crianças, adolescentes e adultos; foram estabelecidas. Como expressão máxima da época, temos a criação da Consolidação das Leis do TrabaIho - CLT em $1^{\circ}$ de maio de 1943 , criada pelo Decreto-lei n. 5.452.

No campo do lazer também foram realizadas, medidas com o intuito de regular o tempo de não trabalho. Pois, com a regulamentação da jornada de trabalho a população em geral passou a ter um tempo de não trabalho maior o que trazia algumas preocupações.

Era receio das classes dominantes que o tempo de lazer, poderia transformar-se no desgaste de sua mão de obra devido aos tipos de diversões realizadas pelos trabalhadores.

Como também o receio de neste momento disponível as pessoas começarem a pensar em superar suas condições péssimas de existência, o que implicaria na mudança das relações sociais de produção (MELO e JUNIOR, 2003).

Neste sentido, com apoio do Estado as classes dominantes organizaram um conjunto de ações com o intuito de regular o lazer para que ele possa: de um lado repor as energias gastas no trabalho e de outro ser educativo em termos disciplinares.

Assim, a partir de 1920 promoveu-se a reorientação das atividades populares, desenvolvendo-se 
também centros recreativos para as classes operárias brasileiras. Em 1926, na cidade de Porto Alegre foi criado o Serviço de Recreação Pública que tinha "como objetivo ocupar adequadamente as "horas de lazer" dos jovens evitando que eles se sujeitassem a delinqüência e à ociosidade" (MARCASSA, 2004, p. 197).

Em São Paulo, por volta de 1935, é criado o Serviço Municipal de Jogos e Recreio que tinham a função de equacionar os problemas higiênicos, recreativos e educacionais, necessários à manutenção da ordem social e municipal (MARCASSA, 2004). Neste período também são criados na cidade os Parques de Jogos, com seus programas para de Parques Infantis e Clubes de Menores Operários (ibid.).

Em 1943 foi criado o Serviço de Recreação Operária do Ministério do Trabalho, Indústria e Comércio. Tal órgão figurou como uma maneira de estender as experiências anteriores no campo do lazer para os menores trabalhadores a todo o território nacional, acompanhando o processo de industrialização que se disseminava pelo território.

E a perspectiva era clara, pois "o lazer não deveria propiciar a realização de qualquer atividade (apenas daquelas consideradas saudáveis e lícitas), e se tornou imprescindível complemento do trabalho produtivo, sendo usufruído justamente em função deste último" (WERNECK, 2003b, p. 43).

Neste sentido, podemos dizer que o trabalho e o lazer se figuravam enquanto direito social e tinham por intenção ingressar a classe trabalhadora seja adulta ou adolescente; nos quadros modernos do processo de industrialização da época e do modo de produção capitalista no Brasil.

Mais especificamente o lazer se constitui enquanto direito social que foi conquistado a duras penas nas disputas entre capital e trabalho ao longo dos séculos passados. Não obstante, como vimos ele foi sendo apropriado pelas elites dominantes em conluio com o Estado de forma a este lazer ter uma função funcionalista ${ }^{8}$ que visa só repor as forças gastas no trabalho.

8 De acordo com Marcelino (1990) as abordagens do lazer podem ser agrupadas em: funcionalista e crítica. No tocante ao funcionalismo (oriundo da Teoria Funcionalista) ele não nasce nas ciências sociais, embora se perceba muito divulgado nessa área. Mas é trazido das Ciências Biológicas. Por essa área de conhecimento a realidade 's posta como dada e o que importa é conhecer o funcionamento dessa realidade. Não há lugar para as contradições, mas sim para a integração (RAMOS, 2001a; RAMOS 2001b). As abordagens funcionalistas compreendem o lazer numa perspectiva acrítica e muito voltada para o senso comum, no que tange ao lazer como simples entretenimento 
Não obstante, as visões de trabalho e lazer enquanto direitos sociais vão passar por mudanças a partir da década de 1970 no mundo e 1990 no Brasil. O que se verá será um recuo do Estado na questão dos direitos sociais nestas duas esferas da vida humana. Diversos estudos têm apontado profundas mudanças no mundo do trabalho (ou mercado de trabalho, para as visões apologéticas) que têm indicado transformações na economia política do capitalismo, no último quartel do século XX e que vem ocorrendo até então (HARVEY, 1993).

A globalização e o neoliberalismo, enquanto grandes processos econômicos e políticos, em curso, têm promovido mudanças estruturais. Aliada e permeada, por estes, temos a reestruturação produtiva, que tem impetrado a partir das inovações tecnológicas, mas não só por conta dessas, mudanças no modo de organização da produção, a qual, um novo modelo se apresenta com o nome de acumulação flexível (HARVEY, 1993).

Tal modelo vai imprimir ao trabalho: a precarização, subcontratação, informalização; fato este que vai ameaçá-lo enquanto direito social. E estas formas perversas vão representar o contexto na qual a constituição brasileira de 1988 vai ser edificada. Um fato relevante é que nesta constituição é retirado o preceito de ser considerado cidadão todo e qualquer pessoa portadora da carteira de trabalho que distinguia os trabalhadores dos vagabundos.

Segundo Organista (2006)

"é instigante atentar que a retirada deste preceito na constituição de 1988 coincide com o contexto histórico que o trabalho formal vai cedendo lugar para o trabalho informal" (p. 23). Isto trouxe para o debate questões importante no que se refere a infância e a adolescência. Dentre elas, gostaríamos de destacar na letra da lei da Constituição de 1988 a questão do trabalho voltada à adolescência: Art. 7o XXXIII - "Proibição do trabalho noturno, perigoso ou insalubre aos menores de 18 anos e de qualquer trabalho aos menores de 16 anos, salvo na condição de aprendiz, a partir de 14 anos" (CONSTITUIÇÃO de 1988).

Deste trecho podemos fazer as seguintes inferências. Primeiro que embora a lei proíba o trabalho infantil, ela não aponta elementos que impeçam concretamente que este não aconteça. Inclusive, acaba ganhando relevância social que crianças menores deveriam trabalhar já que do contrário ficariam na vadiagem ${ }^{9}$. O argumento muito

9 Assim, a criança vai criando outros espaços em instâncias de sociabilidade que podem levá-la a convivência com o mundo das drogas, ao mundo social de violências, do mundo das pequenas infrações, perdendo cm isso a possibilidade de viver a sua infância. 
propalado pelo senso comum é de que "antes trabalhar do que roubar". Mas o que não se percebe é que a criança e o adolescente já pagam por não terem garantidas, em termos de direito social, condições para não terem que exercer tarefas, no mais das vezes degradantes e aviltantes.

Sobre isto, não poderíamos deixar de destacar a fala de Silva (2003), quando coloca que "a criança não é mais aprendiz de ofícios, é diretamente envolvida no mundo do trabalho de forma pervertida e precária, em prejuízo de outras instâncias de sociabilidade, como, por exemplo, da escola, da vizinhança, da comunidade, da praça, do parque, da cultura, etc." (p. 16).

Isto comunga com as discussões no campo do lazer que passa a não ser mais garantido, concretamente, como direito social, já que este fenômeno passa por um processo de mercadorização impedindo que as famílias de baixa renda tenham acesso ao que antes era um direito social garantido pelo Estado (WERNECK, 2000).

Um outro ponto do artigo da Constituição de 1988, supra citado, se refere a aos processos de subcontratação e terceirização vividos pelos chamados aprendizes ${ }^{10}$ (a partir de 14 anos em atividades na qual eles tenham que passar por um processo de aprendizagem profissional), que para complementar as rendas de sua família se sujeitam as mais diversas tarefas que de fato pouco contribuem para uma formação profissional que lhes permita ingressarem no mundo do trabalho visando posições mais bem valorizadas socialmente, ao mesmo passo que impedem os mesmos de usufruírem do direito ao lazer. Mesmo sabendo que o fator econômico é um limitador.

Neste sentido, entendemos que o direito social ao Trabalho e ao Lazer para crianças e adolescentes está pautado numa lógica, que tomamos emprestado de Kuenzer (2002), de inclusão excludente. Esta lógica aponta as seguintes mediações.

No tocante ao trabalho as crianças e adolescentes tem sido incluídas em formas de trabalho totalmente excludentes, que não Ihes garantem uma realidade digna capaz de responder aos anseios da classe trabalhadora em termos da superação das condições históricas contemporâneas.

Já em relação ao lazer essa lógica impõe um duplo movimento,

10 Como exemplos podemos citar os office boys, vigilantes e carros, carregadores de compra; que não tem se quer seus direitos trabalhistas garantidos. Pois, na maioria das vezes assinam um contrato temporário. 
sendo o primeiro referente à utilização do tempo livre como uma esfera de ação lícita, mas vinculada à lógica do trabalho alienado que coloca o lazer como incapaz de tornar um homem mais feliz, mais livre se o trabalho, de igual forma, não lhe proporcionar alegria, oportunidade de criação e realização, enquanto enriquecimento humano (MARCASSA et al., 2005).

Por outro lado, cumpre ressaltar também que sobre o lazer incidem valores comportamentos, significados, e saberes que contribuem para a perpetuação da visão de mundo hegemônica. Ainda sem falar que os momentos de lazer representam a possibilidade dos jovens criarem e reforçarem seus laços de identidade social, que as crianças interpretam e ressignificam o mundo que as cerca. E é nesse sentido, que sinalizamos para o fato de que ao se apropriarem dos escassos momentos de "tempo livre" e ao trabalho precoce, as crianças, como boa parte dos adultos, são incluídas de forma excludente. Primeiro porque não há interesse do poder público em investir a garantia de uma política de lazer que venha contribuir verdadeiramente para o enriquecimento e emancipação humana. E segundo, pelo fato de que, ao trabalharem desde cedo, muitas crianças ficam com o "tempo livre" muito limitado para a prática do lazer, pois além do trabalho, elas ainda cumprem, na maioria das vezes, algumas horas na escola.

É na certeza de que a discussão ainda merece ser ampliada é que passaremos para as modestas considerações finais.

\section{Considerações finais}

Com base nas análises e discussões feitas compreendemos que a luta pela garantia e direito ao trabalho e ao lazer, perpassa pela transformação das condições históricas e concretas que impedem que o conjunto da humanidade possa usufruir de forma ampla estas principais esferas da vida e que são fundantes do ser humano. Faz-se necessário resgatar a partir da infância e da adolescência a visão do ser humano enquanto sujeito coletivo e histórico capaz de produzir e transformar a realidade que o cerca. É da produção material e simbólica da existência humana, cuja centralidade é dada pelo trabalho, que emerge o lazer.

Entendemos que contemporaneamente falar em direito social perfaz compreender que a presente realidade o nega daí tal tema estar em pauta de discussões e ações. Tratar sobre direitos na sociedade brasileira é um tema complexo, pois os cidadãos são tratados perante a lei de forma desigual. 
O sentido da lógica de inclusão excludente faz com que a lei nem sempre seja respeitada e, por tendenciosa interpretação, pode acabar discriminando e excluindo, isto é, valendo somente para alguns.

\section{Referências}

ANTUNES, Ricardo. Trabalho. In: WERNECK, Christianne Luce Gomes (org.). Dicionário Crítico do Lazer. Belo Horizonte, MG: Autêntica, 2004, pp. 227-232. ASSIS, Sávio. Reinventando o esporte. Campinas, SP: Autores Associados, 2001.

BRACHT, Valter. Sociologia Crítica do Esporte: uma introdução. - $3^{\text {a }}$ edição - ljuí: Ed. Unijuí, 2005. BRUHNS, Heloísa Turini. Lazer, Trabalho e Tecnologia: refletindo sobre a necessidade de novos conceitos. In: BRUHNS, Heloísa Turini e GUTIERREZ, Gustavo Luis (orgs.). Representações do Lúdico: Il ciclo de debates "lazer e motricidade". Campinas, SP: Autores Associados, Comissão de pós-graduação da Faculdade de Educação da Unicamp, 2001, pp. 71-89.

CHEMIN, Beatris Francisca. O Lazer como Produto do Trabalho. In: MÜLLER, Ademir; DACOSTA,
Lamartine Pereira (orgs.). Lazer e Trabalho: um único ou múltiplos olhares? Santa Cruz do Sul: EDUNISC, 2003, pp. 83-116.

FIOD, Edna Garcia Maciel. Politecnia: a educação do molusco que vira homem. In: AUED, Bernadete Wrublevski. Educação para o (Des)Emprego (ou quando estar liberto da necessidade do emprego é um tormento). $-2^{\text {a }}$ ed. - Petrópolis, RJ: Vozes, 1999, pp. 83-108.

HARVEY, David. Condição PósModerna. São Paulo: Editora Loyola, 1993.

KUENZER, Acácia Zeneida. Exclusão Includente e Inclusão excludente: a nova forma de dualidade estrutral que objetiva as novas relações entre trabalho e educação. In: LOMBARDI, José Claudinei; SAVIANI, Dermeval e SANFELICE, José Luís (orgs.). Capitalismo, Trabalho e Educação. Campinas, SP, HISTEDBR, 2002, pp. 77-98.

MARCASSA, Luciana. Recreação. In: WERNECK, Christianne Luce Gomes (org.). Dicionário Crítico do Lazer. Belo Horizonte, MG: Autêntica, 2004, pp. 196-203.

MARCASSA, Luciana e MASCARENHAS, Fernando. Lazer. In: GONZÁLEZ, Fernando Jaime e FENSTERSEIFER, Paulo 
Evaldo (orgs.). Dicionário Crítico de Educação Física. Ijuí: Inijuí, 2005, pp. 255-259.

MARCELLINO, Nelson Carvalho. Lazer e Educação. - 2a ed. Campinas, SP: Papirus, 1990.

MARX, Karl e ENGELS, Friedrich. A Ideologia Alemã. - $11^{\text {a }}$ ed. - São Paulo: Hucitec, 1999.

MARX, Karl. Manuscritos Econômico-filosóficos. São Paulo: Boitempo, 2004. .O Capital: crítica da economia política. - $2^{\mathrm{a}}$ ed. - São Paulo: Nova Cultural, 1985.

. Salário, Preço e Lucro. Bauru/ SP: EDIPRO, 2004.

MELO, Victor Andrade de eJUNIOR, Edmundo de Drummond Alves. Introdução ao Lazer. Barueri, SP: Manole, 2003.

NOGUEIRA, Maria Alice. Educação, Saber, Produção em Marx e Engels. São Paulo: Cortez: Autores Associados, 1990.

ORGANISTA, José Henrique Carvalho. O Debate sobre a Centralidade do Trabalho. $-1^{\text {a }}$ edição - São Paulo: Expressão Popular, 2006.

RAMOS, Marise Nogueira. Da qualificação à competência: deslocamento conceitual na relação trabalho - educação. Tese de doutorado, UFF: Niterói, 2001 .
. A Pedagogia das Competências: Autonomia ou Adaptação? São Paulo: Cortez, 2001b.

SILVA, Maria Liduína de Oliveira. Adultização da Infância: o quotidiano das crianças trabalhadoras no Mercado Ver-o-Peso, Belém do Pará, Brasil. Website: www.cpihts. com/2003_08_07/adulinf.htm. Acessado dia 12/09/2006.

WERNECK, Christianne Luce Gomes. Lazer, Trabalho e Educação: relações históricas, questões contemporâneas. Belo Horizonte, MG: Ed. UFMG; CELAR-DEF/UFMG, 2000. - Recreação e Lazer: apontamentos históricos no contexto da educação física. In: WERNECK, Christianne Luce Gomes e ISAYAMA, Hélder Ferreira (orgs.). Lazer, Recreação e Educação Física. Belo Horizonte: Autêntica, 2003a, pp. 15-56.

. Lazer e Trabalho no contexto urbano: reflexões sobre os "clubes operários" (1937-1947). In: In: MÜLLER, Ademir; DACOSTA, Lamartine Pereira (orgs.). Lazer e Trabalho: um único ou múltiplos olhares? Santa Cruz do Sul: EDUNISC, 2003b, pp. 27-44). 
Ano XXIII, $n^{\circ} 36$, junho/2011

\section{ABSTRACT}

The present article has for intention to argue the relations between work, leisure, infancy and adolescence, in our times, on the basis of the changes why it comes passing the countries of the peripheral capitalism in Latin America. Work and leisure are spheres inseparable central offices and it human being and which it cannot do without to exist. What it is come close evidencing is that these come passing for a process of exculpatory inclusion. One becomes necessary to rescue from infancy and of the adolescence the vision of the human being, while subject collective and historical capable to produce and to transform the reality that the fence.

Key Words: Work, Leisure, Exculpatory/Inclusion.

Recebido: fevereiro/2011. Aprovado: julho/2011. 